\title{
PANORAMA DAS POLÍTICAS CULTURAIS NO MUNDO
}

Antonio Albino Canelas Rubim rubim@ufba.br

\section{Invenção contemporânea das políticas culturais}

O tema do surgimento das políticas culturais não é um assunto destituído de polêmicas. Não cabe aqui fazer uma arqueologia exaustiva do seu momento inaugural no mundo ou, pelo menos, no ocidente. As posições de grande parte dos autores que já se debruçaram sobre a temática comportam variações nada desprezíveis, mas parece existir alguma mínima convergência acerca de alguns aspectos. Tal convergência permite que, por exemplo, um estudioso como Xan M. Bouzadas Fernandez (2007a, p. 113, tradução nossa) escreva:

Se nos atemos aos diagnósticos efetuados acerca do nascimento das políticas culturais nos países ocidentais, pode se afirmar que o período geralmente reconhecido como 
fundacional, que pode ser entendido já de um modo pleno como políticas culturais, seria aquele que se estende entre a década dos anos trinta e os anos sessenta do passado século XX.

Depois desta afirmativa, são listados três experimentos que, conforme o autor, podem se constituir em inaugurais: as iniciativas político-culturais da Segunda República Espanhola nos anos trinta do século passado; a instituição do Arts Council na Inglaterra na década de quarenta e a criação do Ministério dos Assuntos Culturais na França, em 1959. Entretanto o próprio autor reconhece que a iniciativa francesa é a mais estudada e possui maior envergadura, pois: “a criação do Ministério de Cultura na França, constitui dentre elas a experiência mais acabada de institucionalização da cultura”. (FERNÁNDEZ, 2007a, p.113)

Deste modo, a criação do Ministério dos Assuntos Culturais na França, com André Malraux em sua direção, pode ser tomada como momento de fundação das políticas culturais, pelo menos no ocidente. Mas a construção de marcos que tentam impor fronteiras aos complexos movimentos históricos é um processo sempre polêmico.

A missão de Malraux não foi apenas instituir o primeiro ministério da cultura existente no mundo, mas conformar uma dimensão de organização nunca antes pretendida para uma intervenção política na esfera cultural. Como assinalou Herman Lebovics (2000, p. 292):

Cabe destacar um fato de importância: Malraux estabeleceu o principio conforme o qual as autoridades públicas têm responsabilidade com a vida cultural de seus cidadãos, do mesmo modo que a têm [...] com sua educação, saúde e bem estar. 
A intervenção do novo Ministério, não se deve esquecer, objetivava também a retomada do poderio cultural francês no ocidente e no mundo, bastante abalado no período posterior à Segunda Guerra Mundial, mas subordinava claramente esta perspectiva política a uma finalidade cultural. Historicamente, a relação entre cultura e política foi sempre marcada pelo predomínio da finalidade política e pela instrumentalização da cultura. Agora acontece uma radical guinada, na qual a cultura é o fim e a política apenas o recurso para atingir este fim.

Assim, André Malraux, com seu Ministério dos Assuntos Culturais, "inventou", no dizer de Philippe Urfalino (2004) em seu já clássico livro, a política cultural em sua acepção contemporânea.

Além da invenção da política cultural em sua concepção atual, o experimento de Malraux à frente do Ministério produziu também outra contribuição essencial: ele conformou os modelos iniciais e paradigmáticos de políticas culturais, com os quais ainda hoje gestores e estudiosos lidam.

O primeiro destes modelos já se encontrava inscrito nos objetivos definidos pelo decreto de 24 de julho de 1959 que institui o Ministério. De acordo com citação transcrita no texto de Xan Bouzadas Fernández (2007a, p. 124), no documento oficial está escrito:

O Ministério de Assuntos Culturais terá como missão tornar acessíveis as obras capitais da Humanidade [...] ao maior número possível de franceses, garantir ampla difusão a nosso patrimônio cultural, e favorecer a criação de obras de arte e do espírito que a enriquecem.

O decreto de criação e, mais que ele, as casas de cultura, projeto prioritário de André Malraux em seus dez anos na direção do Ministério, conformaram o modelo de democratização cultural, que tem como alicerces: a preservação, a difusão e o acesso ao pa- 
trimônio cultural ocidental e francês canonicamente entronizado como a cultura. Isto é, único repertório cultural reconhecido como tal e, por conseguinte, digno de ser preservado, difundido e consumido pela "civilização francesa". Este patrimônio agora deveria ser democratizado e compartilhado por todos os cidadãos franceses, independente de suas classes sociais. Além da preservação, da difusão e do consumo deste patrimônio, tal modelo estimula a criação de obras de arte e do espírito, igualmente inscritas nos cânones vigentes na civilização francesa e ocidental.

Este primeiro período, durante o qual se plasma o modelo inicial de políticas culturais, está marcado por uma nítida vocação: centralizadora, estatista e ilustrada, com um nítido viés de atenção para os aspectos estéticos e artísticos. (FERNÁNDEZ, 2007b, p. 125) O rebelde ano de 1968 colocou em crise este modelo ao questionar hierarquias e cânones, atingindo e abalando esta visão elitista de cultura. A respeito desta contestação, escreveu Herman Lebovics (2000, p. 282):

Sob o lema da 'imaginação no poder', os estudantes desafiaram o projeto cultural do estado. Derrubaram literalmente as Casas de Cultura que havia criado Malraux. Nos fins do verão, os diretores de todas as Maisons de la Culture se reuniram em Villeurbanne e condenaram em forma unânime a natureza não democrática da política cultural dos últimos dez anos.

O segundo desenho paradigmático surge exatamente por contraposição ao modelo inaugural de política cultural. Ele reivindica uma definição mais ampla de cultura, reconhece a diversidade de formatos expressivos existentes, busca uma maior integração entre cultura e vida cotidiana e assume como condição da política cultural a descentralização das intervenções culturais. (BOLÁN, 2006.) 
O modelo intitulado democracia cultural tem como um de seus polos dinâmicos a criação de Centros de Animação Cultural, menores e menos onerosos que as Casas de Cultura, com financiamento partilhado com as autoridades locais, abertos e receptivos às culturas regionais. Esta alternativa será consolidada com a ascensão de Jacques Duhamel ao ministério da cultura no governo George Pompidou. (FERNÁNDEZ, 2007b, p, 125) A municipalização da cultura está articulada com o movimento de deslocamento do lugar do estado nacional nas políticas culturais francesas. (URFALINO, 2004.)

\section{A UNESCO e a emergência internacional do tema das políticas culturais}

Inventadas as políticas culturais, sua inserção como tema relevante na agenda pública internacional decorre não só do exemplo francês, mas principalmente, da atividade desenvolvida no campo da cultura pela Organização das Nações Unidas para Educação, Ciência e Cultura (UNESCO). A título de demonstração pode-se construir um quadro resumo expressivo, panorâmico e não exaustivo, de sua atuação na área cultural, com bases nos principais pronunciamentos emitidos pela instituição multilateral.

O Quadro 1 dá uma mostra da atividade continuada da UNESCO no campo da cultura, uma das suas três áreas de ação, em conjunto com a educação e a ciência e tecnologia. (EVANGELISTA, 2003) Esta atuação na esfera internacional possibilita debates, forma pessoal e, em especial, agenda temas que vão ter importante incidência no cenário político e cultural. 
Declaração Universal dos Direitos de Autor

Declaração de Princípios de Cooperação Cultural Internacional

Convenção sobre as Medidas que se Devem Adotar para Proibir e Impedir a Importação, a Exportação e a Transferência Ilícita de

Bens Culturais

Convenção sobre a Proteção do Patrimônio Mundial Cultural e Natural

Declaração sobre a Raça e os Preconceitos Raciais

Recomendação Relativa à Condição do Artista

Recomendação sobre a Salvaguarda da Cultura Tradicional e Popular

Declaração Universal sobre a Diversidade Cultural

Convenção sobre a Proteção e Promoção da Diversidade das Expressões Culturais

Quadro 1 - Principais iniciativas culturais da UNESCO

Fontes: Site da UNESCO e bibliografia utilizada.

Esta influência fica ainda mais evidente quando se considera a deliberada intenção do organismo multilateral na perspectiva de atuar ativamente no patamar das políticas culturais. Um outro quadro, tão ou mais sugestivo que o anterior, pode ser esboçado para as iniciativas da instituição na esfera específica das políticas culturais. Nele, pode-se observar a atenção destinada pela UNESCO ao tema das políticas culturais em determinados períodos históricos. O expressivo conjunto de iniciativas concentrado por volta da década de 70, mais precisamente entre 1970 e 1982, torna evidente a prioridade dada ao tema naquela conjuntura social, que, não por acaso, coincide com o momento de mutações das políticas culturais na França, em busca de um novo modelo. 
Declaração Universal dos Direitos de Autor

1952

Declaração de Princípios de Cooperação Cultural Internacional

Convenção sobre as Medidas que se Devem Adotar para Proibir e Impedir a Importação, a Exportação e a Transferência Ilícita de

Bens Culturais

Convenção sobre a Proteção do Patrimônio Mundial Cultural e Natural

Declaração sobre a Raça e os Preconceitos Raciais

Recomendação Relativa à Condição do Artista

Recomendação sobre a Salvaguarda da Cultura Tradicional e Popular

Declaração Universal sobre a Diversidade Cultural

Convenção sobre a Proteção e Promoção da Diversidade das Expressões Culturais

Quadro 2 - Principais iniciativas da UNESCO na esfera das políticas culturais

Fontes: Site da UNESCO e bibliografia utilizada.

Além deste conjunto expressivo de encontros, a UNESCO desenvolveu outras atividades relevantes em políticas culturais. $\mathrm{Na}$ área editorial, por exemplo, ela publicou em 1969, como estudo preliminar e genérico para subsidiar o encontro de 1970, o livro Cultural Policy: a Preliminary Study, primeiro de uma coleção que foi editada ao longo da década de 1970, sob o título Studies and Documents on Cultural Policies. Tal coleção buscou analisar a situação da política cultural em países-membros de todos os continentes. (BARBALHO, 2005, p. 33) O livro de Augustin Girard Cultural development: experience and policies (1972) também traz dados interessantes sobre o assunto.

Acompanhar os temas predominantes nos encontros interessa à reflexão, pois elas expressam preocupações e orientações assumidas. Nesta perspectiva, além dos materiais disponibilizados no site 
da UNESCO, este texto se vale também das análises elaboradas por Guillermo Cortés (2006) e por Eduardo Nivón Bolán (2006).

As temáticas que marcam a conferência inaugural de 1970 buscam impulsionar a atuação dos estados na atividade cultural e a participação ativa da população na cultura, enfatizando o ser humano como princípio e fim do desenvolvimento. $\mathrm{Na}$ conferência regional da Europa o tema destacado é a democratização da cultura. As conferências regionais da África (1975) e da América Latina e Caribe (1978), não por acaso deslocam seu centro de atenções e colocam em cena o tema da identidade cultural, que reaparece com força e ligado ao patrimônio na Conferência Mundial acontecida em 1982, na cidade do México. Nela, outros assuntos assumem importância, tais como: impulsionar o desenvolvimento cultural; indicar que este processo requer afirmação cultural (identidade, patrimônio e criatividade) e a famosa nova definição (ampla) de cultura, que tanta repercussão tem nas intervenções posteriores da UNESCO e nas políticas culturais elaboradas em todo mundo. Devido ao seu amplo impacto, interessa relembrar este célebre definição:

[...] a cultura pode ser considerada [...] como o conjunto dos aspectos distintivos, espirituais e materiais, intelectuais e afetivos que caracterizam uma sociedade ou um grupo social. Ela engloba ademais das artes e as letras, os modos de vida, os direitos fundamentais ao ser humano, os sistemas de valores, as tradições e as crenças. (CORTÉS, 2006, p. 25)

Por fim, em 1998, na Conferência Intergovernamental sobre Políticas Culturais para o Desenvolvimento, outras e novas questões ganham relevância, tais como: a integralidade e transversalidade da cultura e da política cultural; a política cultural como dado central da política de desenvolvimento (sustentável) e o patrimônio imaterial/intangível. 


\section{Políticas culturais em cena: primeiro episódio}

A invenção francesa das políticas culturais na contemporaneidade e a amplificação de sua vigência internacional, patrocinada pela UNESCO, possibilitam que o período compreendido entre os anos 1970 e os inícios dos 1980 seja perpassado pela primeira emergência do tema na cena pública mundial, com significativas repercussões em inúmeros países. Eduardo Nivón Bolán (2006) sugere a generalização do compromisso dos estados com o bem-estar de seus cidadãos, acontecida naqueles anos, em especial nos países desenvolvidos, como um dos motivos para a ampliação do alcance das políticas culturais.

A primeira emergência do tema das políticas culturais tem singularidades sobre as quais é preciso refletir. De imediato, sua íntima relação com a questão nacional: seja em seu nascedouro francês; seja na sua internacionalização via UNESCO. Trata-se, então, fundamentalmente, de articular cultura e nação. Ou melhor, de assinalar e desenvolver o papel estratégico da cultura na construção e/ou consolidação do nacional. Por certo, outras temáticas estão presentes - tais como patrimônio, desenvolvimento etc. mas a discussão da cultura e das políticas culturais está centralmente associada ao horizonte de afirmação das nações. Deste modo, a conformação da identidade nacional, operada pelo acionamento da cultura, fundamenta sua centralidade e legitima as políticas culturais naquela conjuntura.

A associação entre cultura, estado e identidade nacional é, então, possível em um instante no qual a nação se constitui no alicerce de organização do sistema mundo e ainda não está sendo colocado em questão pela nova ordem e circunstâncias societárias que estão se configurando e que logo irão marcar a contemporaneidade com uma nova dinâmica, conformada por um outro 
momento do capitalismo (cognitivo); pela globalização neoliberal (HOBSBAWM, 1995) e pela proliferação das comunicações e das redes. (CASTELLS, 1996, 1998)

A hegemonia neoliberal determina o colapso desse movimento, ao impor a retração do estado e ao inibir sua iniciativa em quase todas as áreas de atuação, inclusive na cultural. Procedimento semelhante e simultâneo ocorre no panorama internacional relativo a algumas organizações multilaterais e seus vínculos com a cultura. Na época, o declínio das atividades da UNESCO é visível, inclusive por conta da saída de países como os Estados Unidos da América e o Reino Unido. Ele pode ser constatado pela observação atenta do quadro anteriormente elaborado sobre o assunto. A centralidade então atribuída à cultura e ao modo de conceber as políticas culturais é colocada em questão pela emergência internacional de uma ordem neoliberal, a partir das experiências inglesa e norte-americana, e pela disjunção acontecida entre as políticas culturais e a questão nacional. Daí o colapso da primeira emergência das políticas culturais no cenário mundial.

A ausência do tema das políticas culturais no cenário internacional foi ocasionada pela pretensão do mercado de ser capaz de resolver a questão cultural na nova conformação societária que estava se constituindo com base no "pensamento único". Ou seja, pela prevalência do mercado sobre a política como modalidade de organização da sociedade e da cultura.

\section{Políticas culturais em cena: momento atual}

A caracterização da nova circunstância societária na qual acontece a segunda e contemporânea emergência das políticas culturais é imprescindível para o debate acerca dos novos desafios das 
políticas culturais hoje. Mas, para o engendramento deste momento atual, cabe igualmente destacar a atuação da UNESCO e todo agendamento público operado, principalmente por ela, do tema "diversidade cultural" que irá permitir o retorno à cena mundial do tema das políticas culturais e redesenhar radicalmente sua inserção no contexto internacional.

Nascido do confronto de interesses entre países acerca de como tratar e localizar a cultura, encarada através da crescente dimensão econômica que ela vem assumindo, o debate foi inicialmente desencadeado pela França, através do acionamento do termo exception culturelle (REGOURD, 2002), para impedir que a cultura fosse tratada como uma mercadoria qualquer como pretendiam alguns países tendo à frente os Estados Unidos da América, e fosse inscrita nos fóruns e procedimentos da Organização Mundial do Comércio. Conforme Serge Regourd (2002), o termo exceção cultural aparece no debate público francês, em 1993, simultaneamente à notoriedade midiática adquirida pelo GATT em sua tentativa, a partir da Rodada do Uruguai, de estender o livre comércio aos serviços e mais especificamente aos bens culturais.

Pouco depois, com a ampliação da discussão, busca-se uma alternativa à inserção da cultura no âmbito da OMC e cada vez mais a UNESCO aparece como lugar alternativo e mais apropriado para acolher e tratar da regulação da cultura no cenário contemporâneo. De modo simultâneo a este processo, o conceito exception culturelle vai perdendo fôlego e uma outra noção, diversidade cultural, ocupa seu lugar, como termo mais adequado ao embate travado. Este último termo não se constitui com base na sempre fragilizada perspectiva de ser tomado como uma exceção, antes ele assume visível positividade, quando inscrito na proposição de que a diversidade cultural é uma das maiores riquezas da humanidade e dos povos. 
A assimilação crescente da temática e o papel desempenhado pela UNESCO colocam esta organização multilateral no cerne do novo momento de visibilidade das políticas culturais na cena internacional. Suas manifestações públicas, expressas em encontros e documentos, configuram este novo cenário, no qual reaparecem e atuam as novas políticas culturais. Documentos como Nossa Diversidade Criadora, ${ }^{1}$ de 1996, relatório da Comissão Mundial de Cultura e Desenvolvimento, instituída pela UNESCO; a Declaração Universal sobre a Diversidade Cultural ${ }^{2}$ de 2001 e a Convenção sobre a Proteção e Promoção da Diversidade das Expressões Culturais ${ }^{3}$ de 2005, aprovados em fóruns da UNESCO, tornam-se desencadeadores e balizadores da emergência das políticas culturais nesta nova circunstância societária.

O contexto de apologia do mercado como ente regulador das dinâmicas da sociedade e da cultura, no qual as políticas culturais pareciam interditadas, já apresenta notável fratura na Declaração Universal sobre a Diversidade Cultural, aprovada em 2001. Seu artigo décimo primeiro é indubitável nesta perspectiva:

As forças do mercado, por si sós, não podem garantir a preservação e promoção da diversidade cultural, condição de um desenvolvimento humano sustentável. Desse ponto de vista, convém fortalecer a função primordial das políticas públicas, em parceria com o setor privado e a sociedade civil. (UNESCO, 2005, p. 211)

A leitura do artigo nono da Declaração também é expressiva. Ele afirma que cada estado deve definir e aplicar sua política cultural, "[...] utilizando-se dos meios de ação que julgue mais adequados, seja na forma de apoios concretos ou de marcos reguladores apropriados". (UNESCO, 2005, p. 211) A Declaração repõe a possibilidade e a necessidade dos estados nacionais desenvolverem políticas culturais neste novo contexto internacional, confrontando a restrição neoliberal relativa à atuação do estado. 
A afirmação do direito dos estados nacionais de desenvolver políticas culturais aparece mais uma vez de modo contundente na Convenção, aprovada em Paris em outubro de 2005. No oitavo objetivo elencado pode-se ler:

Reafirmar o direito soberano dos Estados de conservar, adotar e implementar as políticas e medidas que considerem apropriadas para a proteção e promoção da diversidade das expressões culturais em seu território. (UNESCO, 2006, p. 3)

No mesmo documento, tal proposta é relembrada através de um "princípio diretor" intitulado "princípio da soberania" que novamente reafirma o direito dos estados nações em formular e implantar políticas culturais. Assim, é aberta uma essencial fissura na interdição neoliberal, antes vigente em quase todo mundo, e reaparece legitimado o direito das nações desenvolverem suas políticas culturais.

Mas a UNESCO não apenas busca legitimar internacionalmente o direito soberano dos países de formular e aplicar políticas culturais nacionais. Já no relatório Nossa diversidade criadora, ela havia sugerido um novo patamar a partir do qual as políticas culturais devem ser reformuladas. Conforme a comissão da UNESCO “[...] é necessário que [as políticas culturais] se afastem das noções monolíticas de 'cultura nacional' e passem a aceitar a diversidade". (CUÉLLAR, 1997, p. 310)

Deste modo, a nova conjuntura internacional conforma um horizonte que possibilita uma nova emergência das políticas culturais no cenário contemporâneo. Diferente da situação anterior, quando o tema dominante era a identidade cultural nacional, a circunstância atual coloca no centro do debate o tema da diversidade cultural. Ele transforma-se em polo gravitacional das políticas culturais na contemporaneidade. 


\section{Notas}

${ }^{1}$ Versão, em inglês, disponível em: http://unesdoc.unesco.org images/0010/001055/105586e.pdf. Acesso em: 24 mai. 2012.

2 Disponível em: http://unesdoc.unesco.org/images/0012/001271/127160por. pdf. Acesso em: 24 mai. 2012.

${ }^{3}$ Disponível em: http://unesdoc.unesco.org/images/0015/001502/150224por. pdf. Acesso em: 24 mai. 2012.

\section{Referências}

BARBALHO, Alexandre. Política cultural. In: RUBIM, Linda (Org.) Organização e produção da cultura. Salvador: EDUFBA, 2005. p. 33-52.

BERNARD, François de. Por uma redefinição do conceito de diversidade cultural. In: BRANDT, Leonardo (Org.) Diversidade cultural. São Paulo: Escrituras: Instituto Pensarte, 2005. p. 73-81.

BOLÁN, Eduardo Nivón. La política cultural. Temas, problemas y oportunidades. Cidade do México: Conselho Nacional para a Cultura e as Artes, 2006.

CASTELLS, Manoel. The information age: economy, society and culture. Cambridge: Blackwell, 1996-1998. 3 v.

CANCLINI, Néstor Garcia. Definiciones em transición. In: MATO, Daniel (Org.) Estudios latinoamericanos sobre cultura y transformaciones sociales em tiempos de globalización. Buenos Aires: Clacso, 2001.

CORTÉS, Guillermo. Tan cerca y tan lejos: los vaivenes de las políticas culturales. In: CORTÉS, Guillermo; VICH, Victos (Org.). Políticas culturales. Lima: Instituto de Estudos Peruanos e Instituto Nacional de Cultura, 2006, p. 19-43.

CUÉLLAR, Javier Pèrez de. (Org.). Nossa diversidade criadora. Brasília: UNESCO; Campinas, SP: Papirus, 1997.

DUBOIS, Vincent. La politique culturelle: gênese d'une catégorie d'intervention publique. Paris: Belin, 1999.

EVANGELISTA, Ely. A UNESCO e o mundo da cultura. Goiânia: Editora daUniversidade Federal de Goiás: UNESCO, 2003.

FERNÁNDEZ, Xan Bouzada. Financia acerca del origen y génesis de las políticas culturales occidentales: arqueologías y derivas. O Público e o Privado. Fortaleza, v. 9, jan./jun. 2007a, p. 111-147. 
FERNÁNDEZ, Xan Bouzada. Acerca de algunos cambios recientes en los escenarios de la cultura: secularización y globalización. In: MORATÓ, Arturo Rodríguez (Org.) La sociedad de la cultura. Barcelona: Ariel, 2007b. p. 123-153.

GIRARD, Augustin. Cultural development: experience and policies. Paris: UNESCO, 1972.

HOBSBAWM, Eric. A era dos extremos: o breve século XX: 1914-1991. São Paulo: Companhia das Letras, 1995.

LEBOVICS, Herman. La mission de Malraux. Buenos Aires: Editora Universitária de Buenos Aires: EIDEBA, 2000.

REGOURD, Serge. L'exception culturelle. Paris: PUF, 2002.

RUBIM, Antonio Albino Canelas. Políticas culturais e novos desafios. In: SANTOS, Maria de Lourdes Lima dos; PAIS, José Machado (Org.). Novos trilhos culturais: práticas e políticas. Lisboa: Imprensa de Ciências Sociais, 2010. p. 249-270.

SKOT-HANSEN, Dorte. Danish cultural policy. From monoculture towards cultural diversity. In: International Journal of Cultural Policy. Londres, v. 8, n. 2 , 2002. p. 197-210.

UNESCO. Convenção sobre a proteção e promoção da diversidade das expressões culturais. Brasília, 2006.

. Declaração universal sobre a diversidade cultural. In: BRANDT, Leonardo (Org.) Diversidade cultural. Globalização e culturas locais: dimensões, efeitos e perspectivas. São Paulo: Escrituras: Instituto Pensarte, 2005. p. 207-214.

URFALINO, Philipe. L'invention de la politique culturelle. Paris: Hachette, 2004.

VICH, Victor. Gestionar riesgos: agencia y maniobra en la política cultural. In: CORTÉS, Guillermo e VICH, Victos (Org.). Políticas culturales. Lima, Instituto de Estudos Peruanos e Instituto Nacional de Cultura, 2006, p. $45-70$. 
